\title{
A identificação de conflitos em sala de aula utilizando Visualização de Informações
}

\author{
Carlos Roberto da Silveira Junior ${ }^{1}$, Alex Santos Bandeira Barra ${ }^{2}$, Thiago Ferraz \\ do Nascimento ${ }^{2}$, Wendi Müller Araújo² ${ }^{2}$ \\ ${ }^{1}$ Instituto Federal de Educação, Ciência e Tecnologia de Goiás - Campus Goiânia, \\ Goiânia - GO, Brasil. \\ ${ }^{2}$ Instituto Federal de Educação, Ciência e Tecnologia de Goiás - Campus Inhumas, \\ Inhumas - GO, Brasil. \\ carlos.juniordifg.edu.br, \\ alexbarrago@yahoo.com.br, thiagocok@gmail.com, wendimiiller@gmail.com
}

\begin{abstract}
In the school environment social relationships are formed and groups are formed. However, conflicts may occur, requiring the intervention of professionals in education to identify and try to solve such problems. This work proposes information visualization software that generates graphical representations of relationships, as a diagnostic support tool. In order to do so, graphs were defined for the visual representation of relationships and different types of relationships among the students were represented. As a result, psychologists and pedagogues were able to record inferences and pointed out that graphs facilitate the perception of social relationships, demonstrating that the application can be useful.
\end{abstract}

Resumo. No ambiente escolar constroem-se relações sociais e formam-se grupos. Porém, podem ocorrer conflitos, sendo necessária a intervenção de profissionais de educação para identificar e tentar solucionar tais problemas. Este trabalho propõe um software de visualização de informações que gera representações gráficas de relacionamentos, como ferramenta de apoio diagnóstico. Para tanto, definiram-se grafos para a representação visual dos relacionamentos $e$ representou-se diferentes tipos de relações entre os alunos. Como resultado, psicólogos e pedagogos puderam registrar inferências e destacaram que os grafos facilitam a percepção das relações sociais, demonstrando que o aplicativo pode ser uma ferramenta de apoio útil.

\section{Introdução}

A educação tem uma tarefa importante nas escolas, sobretudo com o aumento da violência, impulsionado pela mídia, bullying contra crianças e adolescentes, desestruturação familiar, além das dificuldades socioeconômicas porque passa nosso país. A facilidade de acesso às redes sociais têm produzido um aumento crescente de discussões o que, por vezes, leva a debates, que vez ou outra, entram em conflitos com valores e geram, como conseqüências, atitudes de desrespeito e agressividade.

A escola educa de maneira formal, a sociedade de maneira informal (Libâneo 1998). Não há como negar o papel das mídias na vida dos adolescentes, sua influência positiva e negativa têm crescido assustadoramente. A escola, portanto, tem um papel importante, já que na escola há elementos de identificação (Freud 1996), isto é, os professores são 
vistos como exemplos de adultos e de profissionais. Entretanto, nas últimas décadas, percebe-se que o estudante perde a identificação do professor, perdendo o respeito, o que impacta diretamente na violência escolar contra o profissional da educação, influenciando sobretudo em sua saúde emocional e no conteúdo desenvolvido em classe (Plassa, Paschoalino e Bernardelli, 2021).

A educação é a representatividade de um processo que prepara o cidadão para a vida. Nesse processo há mediações ${ }^{1}$ para o desenvolvimento afetivo, motor, moral e intelectual, social e estético (Libâneo 2004) buscando formar verdadeiros cidadãos de bem com uma moralidade adequada ao bom convívio social. É difícil dizer que tipo de moralidade é mais adequada, mas o que se sabe, de maneira quase consensual, é que a violência exagerada não é um modelo adequado de convivência social. Como afirmam, Strey e Kapitanski (2011, p. 73): "Viver coletivamente requer certa confluência de valores, hábitos e atitudes, o que a educação formal tem como principal meta a ser alcançada".

Se no início das escolas o aspecto intelectual e moral eram os elementos mais importantes, hoje pode-se compreender que há mais desafios para a escola. Não adianta um bom incentivo cognitivo se a base moral como o respeito, por exemplo, não é levado em conta. Quem não dá valor na vida dificilmente dará valor nos estudos, isso é visível no cotidiano escolar: o elemento moral e social são essenciais no modelo de escola da atualidade.

$\mathrm{Na}$ escola, onde grande parte das pessoas passam sua infância e adolescência, o mundo se expande e os contatos sociais primários, com forte base emocional, deixam de ser exclusividade da família. Nesse ambiente, é possível identificar a formação de novos grupos, resultado de relações de afeição ou rejeição. Segundo Oliveira (2000, p. 67), "grupo social é a reunião de duas ou mais pessoas associadas pela interação"'. Devido à interação social, os grupos mantêm uma organização e são capazes de ações conjuntas para alcançar objetivos comuns a todos os seus membros.

Assim como na sociedade e na família, também na escola ocorrem conflitos. A sociedade atual está inserida em um contexto global de intensa quantidade de informações através dos meios tecnológicos, o que gerou novas formas de relacionamento e interação social. Para que a educação acompanhe esse ritmo acelerado em que a sociedade se encontra, ela precisa estar consciente de seu novo papel transformador, contribuindo para que as novas gerações sejam iniciadas no respeito, sobretudo, à condição humana.

Existe um grande esforço de profissionais da educação e lideranças governamentais para desenvolver programas e práticas que incluam no ambiente escolar o indivíduo, a fim de amenizar injustiças sociais. Para Stainback e Stainback (1999), o ensino inclusivo é a prática da integração de todos, independentemente de seu talento, deficiência, origem socioeconômica e cultural, em escolas e salas de aulas provedoras, onde as necessidades dos alunos possam ser satisfeitas ${ }^{2}$.

1 Libâneo (2012) caracteriza o ensino como a "atividade de mediação para promover o encontro formativo - afetivo, cognitivo, ético, estético - entre o aluno e o objeto de conhecimento, ou seja, a confrontação ativa do aluno com a matéria, destacando-se o papel das condições concretas para a realização dessa atividade".

$2 \mathrm{O}$ debate em torno das práticas pedagógicas da educação especial não serão expressos neste artigo, embora se possa citar a visão inatista $\mathrm{x}$ visão interacionista. 
Entretanto, quando se deseja integrar em um mesmo espaço pessoas diferentes, dando oportunidades iguais a todos, inclusive a grupos de indivíduos historicamente desprivilegiados, é natural o surgimento de conflitos, alguns simples e passageiros como pequenas discussões, outros graves e duradouros como atitudes discriminatórias. Tais problemas, se não forem tratados, podem gerar consequências como isolamento, depressão, bullying, agressão física, além de afetar o desenvolvimento de suas habilidades cognitivas e, consequentemente, o desempenho escolar. Ou seja: o fracasso escolar está diretamente ligado ao bom convívio social na escola, embora esse não seja um fator exclusivo.

É importante destacar que aqueles alunos que recebem mais atenção são aqueles que apresentam algum tipo de limitação física ou mental declarada e comprovada por meio de relatório médico (Martínez 2005). Os demais alunos só são alvo de atenção em casos específicos, reconhecidos em conselhos de classe de professores, quando apresentam mau comportamento ou desempenho escolar ruim. Segundo Martínes (2005) se considerar que muitos alunos são agressivos, desmotivados e apresentam dificuldades para aprender, há a necessidade de se trabalhar, prioritariamente, os elementos subjetivos que podem estar sendo obstáculos para a inclusão destes alunos.

O trabalho dos psicólogos e pedagogos pode ser de fundamental importância para diagnosticar e tratar problemas de relacionamento e exclusão social. Segundo Peres e Silveira (2011) a Psicologia é uma das ciências que confere sustentabilidade às teorias pedagógicas e permite a produção de conhecimento sobre os sentidos subjetivos que integram as complexas configurações da escola. Segundo Noronha (2007), a avaliação psicológica é um processo de coleta de dados, cuja realização inclui métodos e técnicas de investigação, tendo o diagnóstico como ponto de partida e a intervenção como ponto de chegada.

Existem algumas ferramentas que permitem a identificação de relações sociais na escola, como o CASSS (Child and Adolescent Social Support Scale) (Malecki e Demaray 2002) e o BASC (Parent Rating Scale of the Behavior Assessment System for Children) (Reynolds e Kamphaus 1992) entretanto, necessitam de uma grande quantidade de informações e possuem certa complexidade de aplicação, o qual demanda conhecimento profundo sobre a técnica, bem como tempo para obtenção das informações relacionadas. Com efeito, mostra-se relevante uma ferramenta que auxilie, de forma objetiva, profissionais da educação a compreenderem os conflitos escolares. Representando um ponto de partida para um melhor acompanhamento dos alunos de uma sala de aula.

Particularmente, a visualização de informações permite que as pessoas processem toda a informação, tirando partido de suas capacidades de percepção visual e utilizando menos o sistema cognitivo (Carvalho e Marco, 2009). Yau (2012) propõe que uma das formas mais eficazes de exploração da informação é através da visualização, a partir dos números colocados em um espaço visual para que o cérebro dos leitores encontre os padrões. Alguns trabalhos relacionados no uso de visualização da informação na área de gestão educacional são Oliveira et al. (2017) que utilizou alguns instrumentos de visualização da informação para auxiliar professores no acompanhamento da aprendizagem de alunos do curso de programação à distância e Coutinho et al. (2018) que utilizou visualização da informação para analisar a evasão escolar em cursos de graduação. 
Sendo assim, entendendo a necessidade de ferramentas que facilitem as atividades de identificação de relacionamentos interpessoais e de suas consequências no ambiente educacional, bem como reconhecendo que tratam de dados subjetivos, torna-se válida a implementação de uma solução que facilite o processamento e abstração dessas informações. Esse artigo, tem como objetivo apresentar uma ferramenta de apoio na identificação de conflitos no ambiente escolar, a partir da visualização de informações, o qual permita aos educadores reconhecerem, avaliarem e analisarem o relacionamento entre alunos, oferecendo pressupostos para uma melhoria dessas relações.

\section{Metodologia}

Esse trabalho se trata de uma pesquisa empírica em que foram utilizados instrumentos de avaliação e mensuração educacionais. Foram realizadas entrevistas e aplicação de questionários para o desenvolvimento de um software como ferramenta de apoio na identificação dos conflitos na escola. A metodologia foi composta das seguintes etapas: a) Entrevista junto aos profissionais de pedagogia e psicologia que atuam na escola; b) Definição das variáveis e representações visuais capazes de simbolizar relacionamentos; c) Coleta de dados a partir da aplicação de questionário em uma turma do IFG; d) Desenvolvimento do software; e) Avaliação do software.

$\mathrm{Na}$ escola onde a pesquisa foi realizada há uma equipe multidisciplinar, composta por psicólogos, pedagogos e, obviamente, professores e gestores. Estes profissionais da educação trabalham no cotidiano escolar intervindo e tentando compreender os problemas de relacionamentos apresentados na instituição. Foi realizada uma entrevista semi-estruturada com psicólogos e pedagogos da instituição, buscando entender melhor o problema das relações entre alunos na instituição e identificar métodos de apoio diagnóstico com o uso da tecnologia. Para tanto, buscou-se uma abordagem simples, objetiva e de fácil compreensão para os alunos. Com efeito, a equipe multidisciplinar definiu em conjunto com os pesquisadores o uso de uma tabela em que cada aluno deveria responder a afeição em relação aos colegas de sala, sendo as opções de afeição: "Gosto Muito", "Gosto Pouco", "Não Gosto" e "Nenhum/Não opino"3.

A Figura 1 apresenta o diagrama de visão geral do software, os responsáveis (pedagogo ou psicólogo) solicita aos alunos o preenchimento do questionário e realiza o cadastramento dos dados obtidos de cada aluno, em seguida, o software expressa por meio de representações visuais os relacionamentos em uma determinada turma, através do.

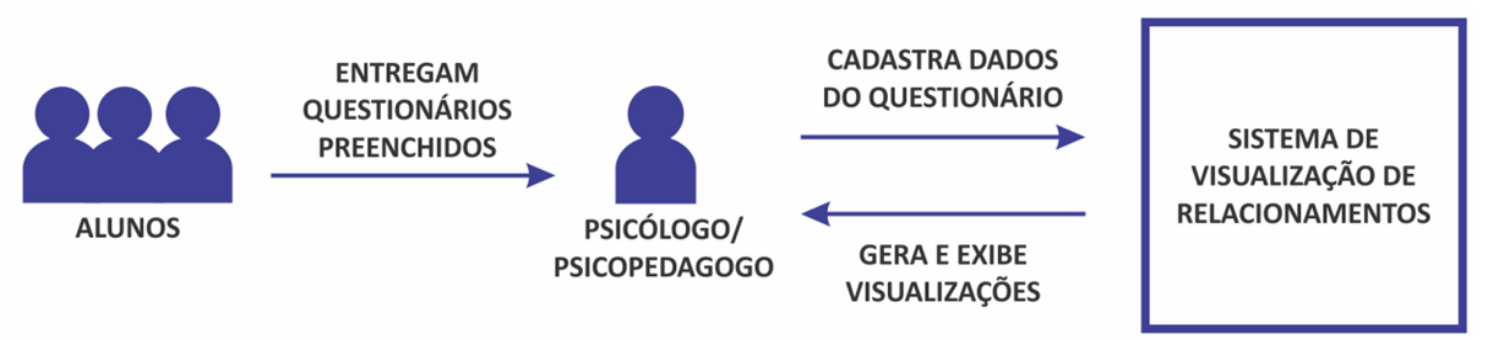

Figura 1. Diagrama visão geral do software.

3 O questionário aplicado ao aluno e o questionário de avaliação da visualização de informação está disponível em: https://github.com/profcarlos/artigos/blob/main/SBIE_2021_VI_Apendice.docx. 
Utilizou-se a técnica da sociometria ${ }^{4}$ que, de acordo com Lakatos e Marconi (2015), permite estudar grupos familiares, de trabalho e escolares: "Revela a estrutura interna dos grupos, indicando as posições de cada indivíduo em relação aos demais, bem como permite analisar os grupos, identificar seus líderes, subgrupos e os desajustados" (Lakatos e Marconi,, 2015, p. 114). Nesta técnica os dados são representados em diagramas, como os grafos orientados que em que as arestas indicam o sentido do relacionamento. $\mathrm{O}$ sentido das setas indica a relação do indivíduo com cada indivíduo do grupo e o comprimento das arestas reforça a representação do nível de afeição através da proximidade ou afastamento do vértice do centro em relação aos vértices das extremidades. O vértice, como a representação do indivíduo, recebe um texto de identificação e assume cinco configurações distintas de cor. O vértice localizado no centro refere-se ao aluno que está em foco e assume a cor branca com contorno preto.

Após essa etapa, foi utilizada a técnica de Visualização de Informações para apresentação das informações obtidas a partir dos questionários. No desenvolvimento do software foram utilizados o Graphviz para gerar as visualizações dos grafos (Graphviz 2019), seguindo o modelo de referência de visualização de informações de Card et al. (1999) apud Nascimento e Ferreira (2011, p. 18), utilizando como linguagem de programação o JAVA e no desenvolvimento do sistema e do banco de dados, o Postgree SQL. Segundo Dondis (2003) para analisar e compreender a estrutura total de uma linguagem visual, é conveniente concentrar-se nos elementos visuais individuais.

Assim, utilizou-se cores para identificação do tipo de relacionamento, quanto ao nível de afeição: verde, "Gosto Muito"; amarelo, "Gosto Pouco"; vermelho, "Não Gosto"; e cinza para "Nenhum/Não opino". Para a apresentação dos dados foi utilizado um gráfico em barras apresentando a somatória da quantidade de opiniões de cada um dos níveis de afeição. Para representação dos estudantes e separação por gênero foram utilizados os termos "aluno" e "aluna". Os alunos foram numerados sequencialmente, independente do gênero.

Com o intuito de permitir diferentes visualizações, baseado nas características definidos pelos próprios usuários na etapa de entrevista, foram criados grafos que permitem visualizações, sendo: a) um grafo para representação das relações do aluno para turma; b) um grafo para representação das relações da turma para o aluno; c) grafos para comparação entre relações de dois alunos sendo dois grafos do aluno para a turma e dois grafos da turma para o aluno; d) um grafo para representação das relações entre mesmo gênero ou gênero oposto.

$\mathrm{Na}$ fase final foi realizada uma coleta de dados com 19 estudantes, através do preenchimento de dados pessoais e de uma tabela sobre o nível de afeição correspondente a cada um. A aplicação foi feita numa turma de ensino técnico em Informática do Instituto Federal de Goiás, campus Inhumas, no ano de 2016. As inferências foram testadas no software pelos profissionais envolvidos na pesquisa. Para formalização das opiniões e percepções dos entrevistados, foi aplicado questionário com questões abertas e de múltipla escolha, incluindo campo para inserção dos "insights" gerados e aspectos da turma avaliada.

4 Jacob Moreno é o fundador do Psicodrama. Abordagem terapêutica ligada à Psicologia. 


\section{Resultados e Discussões}

Na visualização das relações do aluno para a turma é possível que o usuário visualize o que o aluno respondeu em seu questionário, em relação a cada um de seus colegas, conforme a Figura 2. Também se tem a possibilidade de gerar a visualização inversa, ou seja, das relações da turma para o aluno, correspondente às respostas dos colegas a respeito do aluno. Observa-se no canto inferior direito a presença do gráfico de barras para apresentação dos dados.

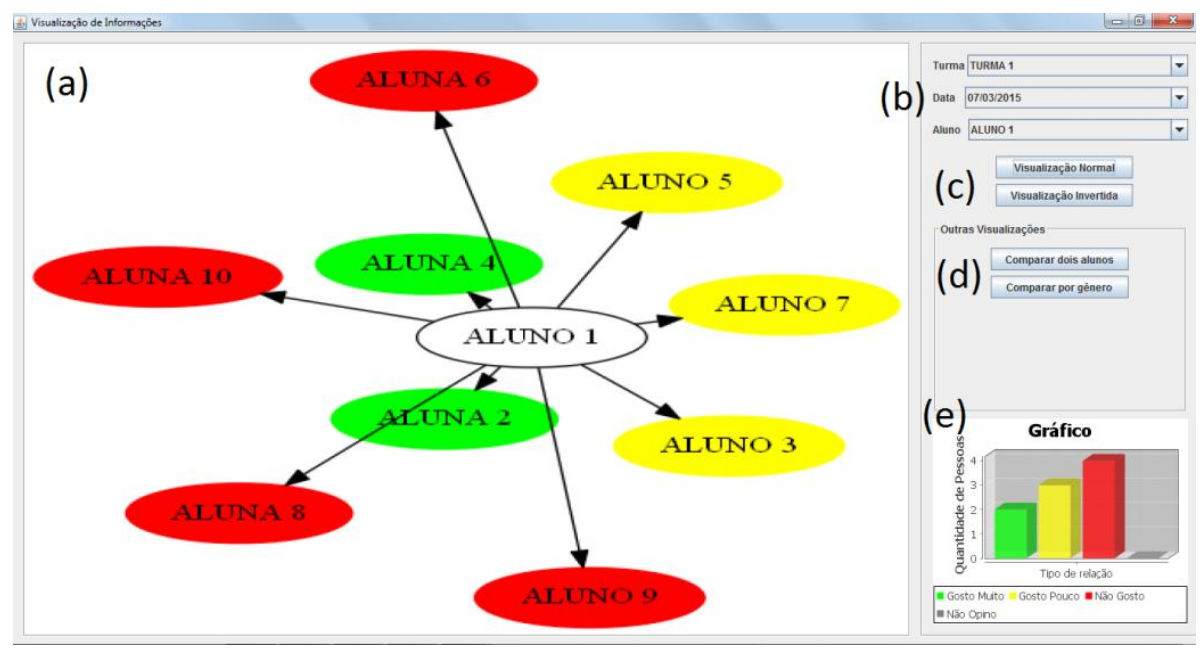

Figura 2. Visualização da relação do aluno 1 com a turma. Sendo formado pelo grafo direcional (a), opções de turma, data e aluno (b), opções de mudança de sentido do grafo (c) e opções de outras visualizações (d) e gráfico de barras (e).

Na Figura 2, vê-se que o "aluno 1" gosta muito de duas alunas, gosta pouco de outros três alunos e não gosta de outros quatro colegas. Tais informações por si só já tem uma validade no acompanhamento psicopedagógico, pois, em geral, as pessoas não falam o que pensam dos outros. Esse tipo de pergunta, feita aos alunos, serve para adentrar nos conflitos presentes nas turmas. Em geral, a coordenação e equipe pedagógica não percebem os conflitos de forma tão direta, visto que esses se mostram de forma disfarçada $^{5}$. Dessa forma, quando um determinado estudante é questionado de como enxerga a turma, pode trazer benefícios para um trabalho individual ou mesmo coletivo da turma. Por outro lado, a Figura 3 apresenta uma visão contrária, a relação da turma com o aluno 1. Observa-se que grande maioria da turma gosta muito da aluna, porém, uma aluna gosta pouco e um aluno não gosta dela. Quando uma turma gosta bastante de uma estudante, isso nos levou a pensar em quais mecanismos estão presentes naquela pessoa que é mais admirada. O software gerou na equipe pedagógica uma reflexão de quais aspectos carismáticos existem naquela estudante e que poderiam, inclusive, servir como exemplo para outros estudantes.

O software possibilita uma inserção nos mecanismos psicossociais, isto é, entender quais mecanismos de identificação, por exemplo, estão sendo produzidos em determinada turma. Conforme apontou Freud, a identificação instaura no sujeito uma

5 Usando o linguajar jungiano poderíamos dizer que os estudantes mais francos são aqueles que usam mais sua "sombra", ao contrário dos estudantes que respondem de forma mais convencional, isto é, não falam exatamente aquilo que pensam. Estes têm mais "máscaras" a serem quebradas. (Hall; Lindizey; Campbell. 2000). 
relação de afeto que pode ser positiva ou negativa. No caso da estudante que é mais admirada na turma, é de se supor que sua forma de interação com os demais colegas deve ser mais livre e solta. Embora isso seja uma inferência, o aplicativo serve para elaborar reflexões sobre como os adolescentes se relacionam. Há elementos afetivos, amor e ódio, presente em suas relações.

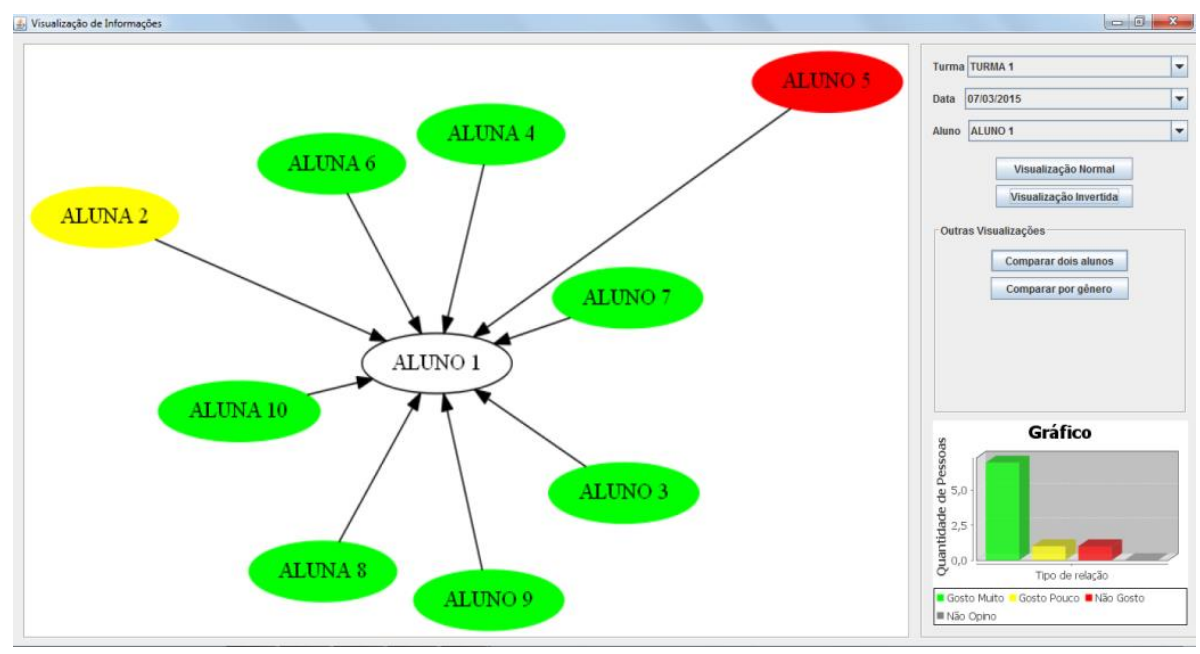

Figura 3. Visualização da relação da turma com o aluno 1.

Analisando as imagens percebe-se que existe reciprocidade na relação entre o aluno $1 \mathrm{e}$ a aluna 4, ambos responderam que gostam muito um do outro. Entretanto, também existem relações com menor reciprocidade, como entre o aluno 1 e a aluna 2 em que o aluno 1 informa que gosta muito da aluna 2 mas a aluna 2 informa que gosta pouco da aluna 1. Havendo ainda, relações ambíguas em que o aluno 1 informa que não gosta dos alunos 6, 8, 9 e 10, entretanto, tais alunos informam que gostam do aluno 1. Essas visualizações demonstram problemas de relacionamento na sala e servem como ponto de partida para ser feito um trabalho psicopedagógico com a turma.

Outra visualização permite comparar a relação entre aluno e turma para dois diferentes alunos, conforme apresentado na Figura 4. Os quadros indicam as visualizações de aluno para a turma (Fig. 4a e Fig. 4c) e da turma para o aluno (Fig 4b e Fig. 4d), respectivamente, para o aluno 1 e aluna 2.

Nesta visualização percebem-se outros problemas de relação, por exemplo, o aluno 1 gosta muito da aluna 2 mas não gosta da aluna 10, por outro lado, a aluna 2 gosta pouco da aluna 1 e gosta muito da aluna 10. Isso demonstra a complexidade de relações sociais bem como a relevância de observação de outras visualizações para abstração de mais informações e obtenção de novos insights, como as visualizações do aluno $1 \mathrm{com}$ aluno 10 e aluna 2 com aluna 10 . 


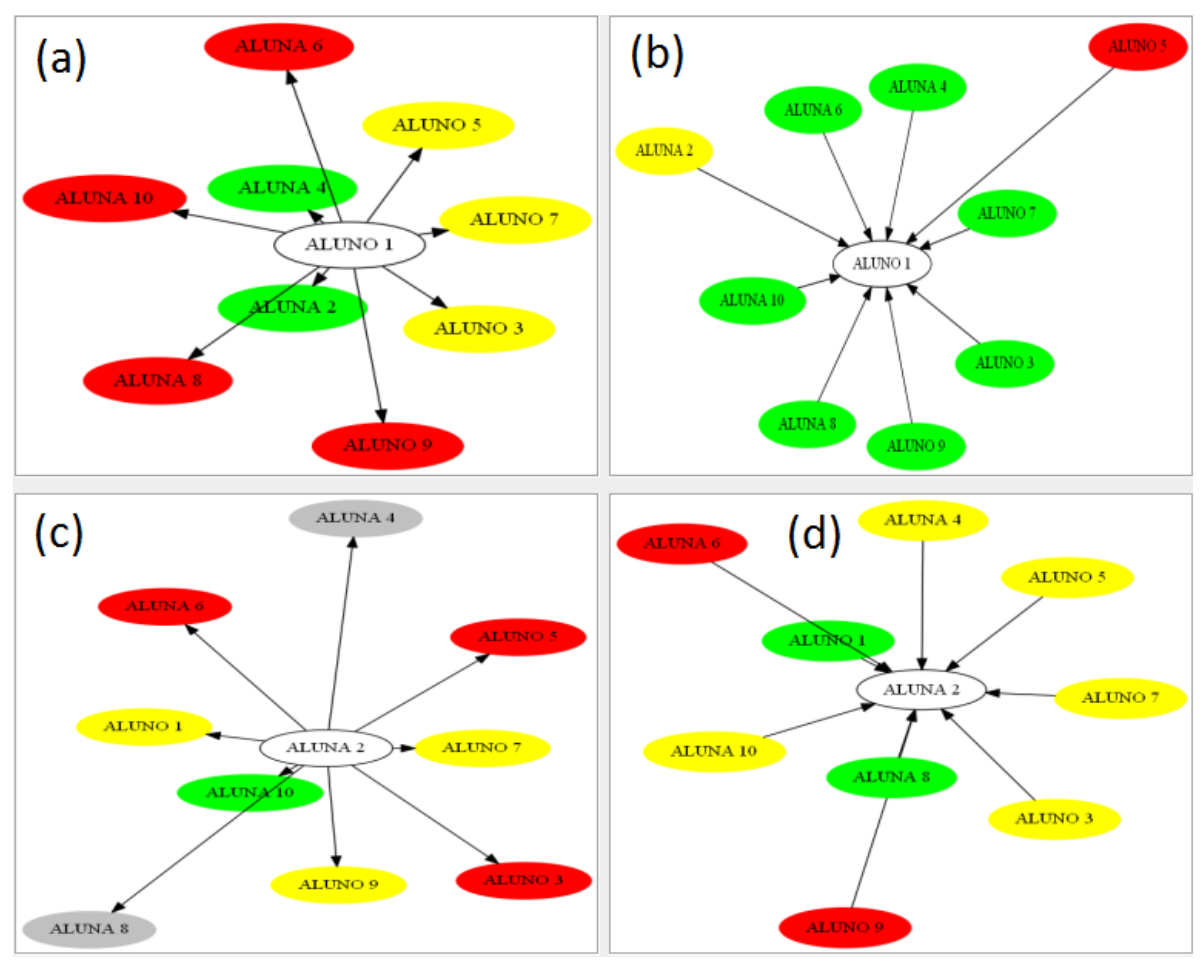

Figura 4. Visualização de comparação entre dois alunos. Sendo os grafos de relação do aluno 1 para a turma (a), da turma para o aluno 1 (b), do aluno 2 para a turma (c) e da turma para 0 aluno 2 (d).

A visualização de gênero permite uma percepção das relações entre alunas e alunos. A Figura 5 apresenta a visualização de gênero da aluna 8 para os alunos da turma e viceversa.

(a)

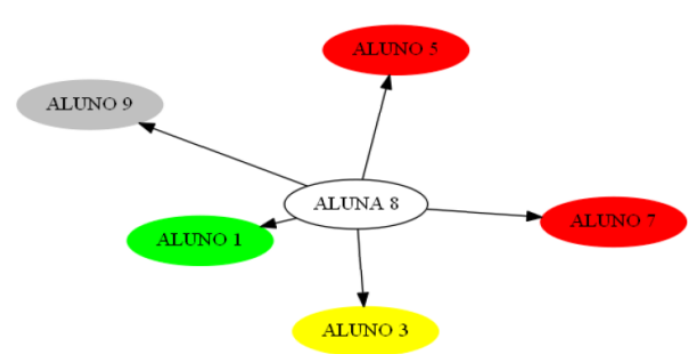

(b)

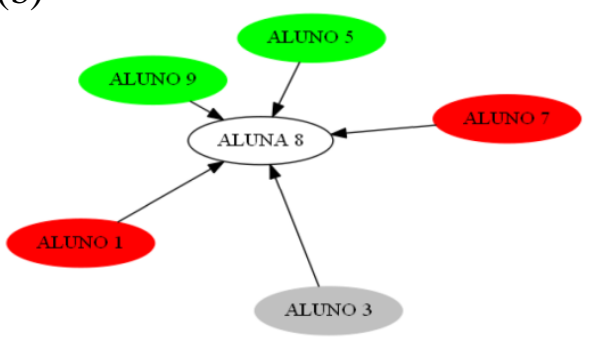

Figura 5. Visualizações de Gênero. Sendo os grafos de relação da aluna 8 para a os alunos da turma (a) e dos alunos da turma para a aluna 8 (b).

Nesta visualização percebe-se uma dificuldade de relação da aluna 8 com os alunos da turma: os alunos que ela relata gostar muito e pouco (Fig. 5a) informaram, respectivamente, que não gosta e não opinou sobre a relação com esta aluna (Fig. 5b).

Segundo os profissionais que analisaram o software, é possível visualizar e entender fatos que ocorrem no cotidiano. Também é possível visualizar a interação dos alunos, e a possibilidade de uma percepção preventiva quanto a possíveis problemas, incluindo-se o bullying. 
Como pontos negativos foram relatados que nem sempre o profissional consegue identificar os alunos somente pelo nome. Para resolver este problema poderiam ser inseridas na visualização fotos dos alunos. Os dois profissionais entrevistados classificaram o software como "Muito útil". As representações visuais apresentadas no software foram bem-aceitas pelos profissionais da escola e classificadas como relevantes e facilitadoras da compreensão dos dados apresentados.

De acordo com estes profissionais, a ferramenta serve para identificar conflitos na escola, além de facilitar a percepção de casos de exclusão, isolamento social, formação de grupos e discriminação social. Em termos de aspectos gerais, os entrevistados tiveram dificuldades de avaliar quando o profissional não conhecia a turma. Sendo que neste caso fica mais fácil analisar o aluno isoladamente.

\section{Conclusões}

A simplicidade da informação, aliada à simplicidade da representação visual, permitiram a compreensão das diversas relações sociais da sala de aula pelos profissionais de educação. O software aplicativo resultante deste estudo foi testado por profissionais de educação, que aprovaram o sistema, atribuindo a ele utilidade em possíveis práticas cotidianas.É importante destacar que o software pode funcionar como uma ferramenta de apoio educacional, cabendo ao profissional em educação interpretar as informações e relatar possíveis ações de intervenção para a melhor qualidade das relações do ambiente escolar.

As críticas foram úteis para a identificação de possibilidades de aprimoramento da ferramenta. Sendo assim, uma nova versão do software poderá ser mais interativa, por exemplo, oferecendo fotos e informações básicas dos indivíduos analisados ao passar o cursor do mouse sobre o nó correspondente. O software representa uma inovação tecnológica no estudo de relações sociais, tanto que, como resultado, fez-se o registro de software desse aplicativo no INPI (Instituto Nacional de Propriedade Intelectual) processo $\mathrm{n}^{\circ}$ 512018000330-3 em 26/03/2018, com o apoio do próprio IFG via CITE (Centro de Inovação Tecnológica).

Como trabalhos futuros, espera-se desenvolver uma versão de software Online de acesso gratuito a ser disponibilizado em site institucional para utilização de professores, pedagogos e psicólogos dos cursos técnicos e de graduação. Bem como desenvolver análises automáticas a partir da inclusão de técnicas de Inteligência Artificial.

\section{Referências}

Carvalho, E. S., Marcos, A. F. (2021) "Visualização de informação", http://repositorium. sdum.uminho.pt/bitstream/1822/8863/1/RelatorioCCG-ISBN978972-99062-5-1.pdf, Julho.

Coutinho, E., Bezerra, J., Bezerra, C., \& Moreira, L. 2018 Out 28. Uma Análise da Evasão em Cursos de Graduação Apoiado por Métricas e Visualização de Dados. Anais do Workshop de Informática na Escola. [Online] 24:1

Dondis, D. A. (2003), Sintaxe da linguagem visual, Martins Fontes. 
Freud, S. (1969a). Psicologia de grupo e análise do ego. In S. Freud, Edição standard brasileira das obras completas (J. Salomão, trad., vol. 18, pp. 89-179). Rio de Janeiro: Imago.

Graphviz. (2021) "O que é Graphviz?", https://www.graphviz.org/, Julho.

Hall; Lindizey; Campbell. Teorias da Personalidade - $4^{\mathrm{a}}$ ed.; Porto Alegre: Artmed, 2000 .

Lakatos, E. M. e Marconi, M.A. (2015), Técnicas de Pesquisa, Atlas, $7^{a}$ edição.

Libâneo, J. C. (1998), Democratização da escola pública, Cortez, $20^{a}$ edição.

(2004), Adeus professor, adeus professora? novas exigências educacionais e profissão docente, Cortez, $8^{\mathrm{a}}$ edição.

(2012), Ensinar e aprender, aprender e ensinar: o lugar da teoria e da prática em didática. Temas de pedagogia: diálogos entre didática e currículo, Cortez.

Martínes, A. M. (2005), Inclusão Escolar: Desafios para o Psicólogo. In Martínes, A. M. (Org). Psicologia Escolar e Compromisso Social: novos discursos, novas práticas, Alínea, p. 95-114.

Malecki, C. K. e Demaray, M. K. (2002). Measuring perceived social support: Development of the Child and Adolescent Social Support Scale. In Psychology in the Schools, v. 39, p. 1-18.

Nascimento, H. A. D. e Ferreira, C. B. R. (2011). Uma introdução à visualização de informações. Visualidades, In Visualidades, v. 9, n. 2, p. 13-43.

Noronha, A. P. P., Nunes, M. F. O., Ambiel, R. A. M. (2007). Importância e domínios de avaliação psicológica: um estudo com alunos de Psicologia. Paidéia, v. 17, n. 37, p. 231-244.

Oliveira, M., França, H., Lopes, M., Silva, A., Neves, Á. (2017). Instrumentos de Visualização da Informação para Avaliação Diagnóstica em Curso de Programação a Distância. Anais do Workshop de Informática na Escola. [Online] 23:1.

Oliveira, P. S. (2000), Introdução à sociologia. São Paulo: Editora Ática.

Plassa, W., Paschoalino, P. A. T., Bernardelli, L. V. (2021). Violência contra professores nas escolas brasileiras. Nova Economia, v. 31, n. 1.

Peres, V. L. A. e Silveira, C. A. (2011). Retratos da realidade escolar: aspectos imediatos e mediados. Construção Psicopedagógica. v. 19, n. 18, p. 87-103.

Reynolds, C. R. e Kamphaus, R.W. (2002), The clinician's guide to the Behavior Assessment System for Children (BASC), The Guilford Press.

Stainback, S. e Stainback, W. (1999), Inclusão: um guia para educadores, Artmed.

Strey, M. N., Kapitanski, R. C. (2011), Educação \& Internet: A era da informação e a vida cotidiana, Sinodal.

Yau, N. Visualize Isto: O Guia do FlowingData Para Design, Visualização e Estatística. Rio de Janeiro: Alta Books, 2012. 